\title{
Behavior and properties of tin slag polyester polymer concrete confined with FRP composites under compression
}

https://doi.org/10.1515/jmbm-2020-0005

Received Nov 05, 2019; accepted Jan 07, 2020

\begin{abstract}
Polymer concrete (PC) has acquired niche in construction industry due to superior mechanical properties, recyclability and adoption of variety of aggregates. This work presents compressive behavior and properties of one such novel PC i.e. tin slag/polyester polymer concrete. Comparable siliceous content of tin slag was considered promising to provide better mechanical strength as in natural aggregates. Cylindrical short column specimens were fabricated to be tested under quasi-isostatic loading rate of $1 \mathrm{~mm} / \mathrm{min}$. Three different aggregate sizes in gap-graded configuration were tested to assess influence on mechanical properties. In addition, specimens were confined with GFRP and CFRP to determine and compare mechanical behavior with Portland Cement Concrete (PCC). Coarsest size $(4+2 \mathrm{~mm})$ aggregate offered the highest strength of 37.71 MPa for unconfined sample. This performance of coarsest size persisted in confined condition with compressive strength increment of $69.68 \mathrm{MPa}(84.7 \%)$ and $98.36 \mathrm{MPa}$ (160.8\%) for one and two layers GFRP; $86 \mathrm{MPa}(128.05 \%)$ and $125.07 \mathrm{MPa}$ (231.66)\% for one and two-layer CFRP, respectively. It was concluded that both increment in aggregate size and number of layers improved the compressive strength.
\end{abstract}

Keywords: polymer-matrix composites (PMCs), mechanical behavior, compressive testing, FRP confinement, tin slag/polyester concrete

\footnotetext{
*Corresponding Author: Shukur Bin Abu Hassan: School of Mechanical Engineering, Universiti Teknologi Malaysia, 81310, Johor Bahru, Malaysia; Centre for Advanced Composites, Universiti Teknologi Malaysia, 81310, Johor Bahru, Malaysia; Email: shukur@utm.my; Tel.: +60197626585

Usaid Ahmed Shakil: School of Mechanical Engineering, Universiti Teknologi Malaysia, 81310, Johor Bahru, Malaysia; Centre for Advanced Composites, Universiti Teknologi Malaysia, 81310, Johor Bahru, Malaysia
}

\section{Introduction}

Construction industry has seen a variety of materials, both naturally occurring and by-products, to be used as aggregates from granite, limestone and gravels to fly ash and blast furnace slag [1-3]. These aggregates have been incorporated in both cementitious and non-cementitious matrices for as diverse an application as road pavements, industrial floorings, vibrating machine beds and pre-cast columns [4-6]. However, the modern urge for environmental sustainability and urban service environment fraught with acids have raised a need to not only review the suitability of conventional construction materials but also find their alternatives [7]. This need has diversified the domain of construction practices by creating tolerances for new types of concrete called polymer concrete.

Polymer concrete (PC) is a composite material that consists of a synthetic binder of polymeric nature coated on aggregates. Polymer modified concrete or resin concrete are versatile materials that accept both classes of polymers i.e. thermoset and thermoplastic as matrix. PC concrete gives optimum combination of mechanical strength and chemical resistance, which is an essential factor contributing to better in-service performance. These types of concrete have good durability, damping properties, wide range of modulus available, and fast curing rate. In addition, Polymer concrete are marked by water tightness, high strength and non-corrodibility [5]. There has been a continuous drive in recent years to incorporate industrial by-products and construction waste in PC to assess their mechanical properties and behavior. These studies have been carried out with a view to relate mechanical performance with size, shape, grading of aggregate and resin ratio. Carrión et al. conducted a study to investigate the properties of polyester embedded recycled basalt aggregates taken from concrete sleepers when calcium carbonate was used as micro filler [8]. A linear trend of improved mechanical strength and modulus was found with increment in resin ratio up to a limit, when aggregate size and micro filler content were constant. Jung et al. studied the mechan- 
ical properties of epoxy-concrete by preparing specimen with aggregate-resin ratio of 90:10, 85:15, 80:20, and 70:30 by weight [9]. Two kinds of aggregates were used; coarse $(0.85-1.2 \mathrm{~mm})$ and a fine aggregate $(0.25-0.6 \mathrm{~mm})$ with a mix ratio of 2:1 by weight. Highest compressive strength, modulus and mass density was obtained with $20 \%$ resin mixture. Specimens that had higher aggregate ratio had low mass densities presumably because of high void content. Ferdous et al. investigated the effect of filler ratio on the mechanical properties of PC to determine optimum concentration [10]. Fly ash, hollow microsphere and fireretardant filler blend was incorporated in matrix from $10 \%$ to $60 \%$ by volume. Flexural strength decreased with filler content increment and maximum compressive strength was in the range of $10-30 \%$ filler. Modulus of the system increased with filler increased filler presence.

Literature abounds of studies conducted to ascertain mechanical behavior and properties of confined concrete to know relation with factors such as fiber type, no. of layers, adhesive type, column geometry etc. Xiao et al. prepared concrete test samples confined with both CFRP and GFRP to determine the fundamental compressive behavior [11]. Typical bilinear stress-strain response was observed with hoop tensile strain of 0.007-0.01 for CFRP and 0.01-0.018 for GFRP. These values were about $50 \%$ to $80 \%$ of the values obtained from tensile testing of flat coupon. Strain increment was obvious for low strength and thicker jackets with larger number of plies. Ali et al. prepared concrete cylindrical columns for them to be tested under compression with CFRP confinement. CFRP wrapping was done in three distinct ways: (A) on entire profile, (B) in the middle and at $(\mathrm{C})$ upper and lower end although confinement ratio was held constant [12]. Results revealed that confinement is responsible for both increase in strength and ductility of samples. Higher the ratio of confinement promises larger area under the curve, i.e. ductility. Ghalieh et al. reported stress-strain response of low strength concrete hemp fabric wrapped cylindrical samples [13]. Compression tests were performed on 1, 2, and 4-layer samples to determine the confinement effectiveness. In first linear region, lateral expansion was insignificant and confinement role of jacket was not activated yet. In second linear region, structural behavior of layer becomes active as it started containing lateral expansion of concrete core. Confinement effectiveness, $f_{c c}^{\prime} / f_{c c}^{\prime \prime}$, increased with the increase in number of layers. Proportion of increment was $9.1 \%, 13.3 \%$ and $21.7 \%$ for 1,2 and 4 layers, respectively.

The main objectives of this study are to determine mechanical properties and behavior of both confined and unconfined tin-slag/polyester polymer concrete under compression. As the brittleness and variation in strength of polymer concrete are of obvious concerns that could adversely affect in-service performance, confinement of PC was carried out with one and two layers GFRP and CFRP to assess the ductility and strength enhancement. For that purpose, gap-graded configuration of aggregate was employed with different aggregate sizes to assess their influence on mechanical properties. An analysis of result spectrum along confinement efficiency and ductility indices will help evaluate performances with increment in number of layers.

\section{Experimental}

\subsection{Materials}

Tin-slag was procured from Malaysia Smelting Corporation Berhad, Malaysia. In as-received form, it was blackish and misty. Average particle size of tin-slag has been reported to be passing $3.35 \mathrm{~mm}$ sieve [14]. Angular, flaky and needle-like particles were present with angular shape in abundance. Chemical composition of tin slag is given in Table 1. Higher percentage of silica and oxides have been reported to be instrumental in providing strength to concrete materials [15].

Table 1: Chemical composition of tin-slag [14, 15]

\begin{tabular}{cc}
\hline Properties & Value (\%) \\
\hline Calcium oxide $(\mathrm{CaO})$ & $16-20$ \\
Silicon dioxide $\left(\mathrm{SiO}_{2}\right)$ & $28-32$ \\
Aluminum oxide $\left(\mathrm{Al}_{2} \mathrm{O}_{3}\right)$ & $10-13$ \\
Magnesium oxide $(\mathrm{MgO})$ & $2-4$ \\
Iron $\left(\mathrm{FeO}\right.$ or $\left.\mathrm{Fe}_{2} \mathrm{O}_{3}\right)$ & $13-18$ \\
Wolfram oxide $(\mathrm{WO})$ & 2.0 \\
Arsenic $(\mathrm{As})$ & $<0.01$ \\
Lead $(\mathrm{Pb})$ & $<0.01$ \\
Cadmium $(\mathrm{Cd})$ & $<0.0001$ \\
Titanium dioxide $\left(\mathrm{TiO}_{2}\right)$ & $4-5$ \\
Zinc $(\mathrm{Zn})$ & $<0.3$ \\
Tin $(\mathrm{Sn})$ & $<1.4$ \\
\hline
\end{tabular}

Ortho-pthalic polyester (BIP 2700 AT-1) having thixotropic nature was used as matrix. Viscosity, specific gravity and gel-time were reported to be 3-5 poise, 1.12 $\mathrm{g} / \mathrm{cm}^{3}$ and 10-15 minutes, respectively. Methylethylketone peroxide (MEKP) at a ratio of $2 \%$ by weight of resin was used as initiator. Epicot 2175 epoxy system was used to bond FRP fabric on PC samples. The epoxy-hardener ratio 
was maintained at 4:1. Gel and curing time were reported to be 140 minutes and 24 hours. CFRP and GFRP used for confinement were principally aligned in hoop direction. Properties of FRP laminates with 49.4\% fiber and 50.6\% resin by weight, attainable through hand lay-up technique, as reported by vendor are given in Table 2 .

Table 2: Mechanical properties of FRP laminates (manufacturer data sheet)

\begin{tabular}{ccc}
\hline Property & GFRP & CFRP \\
\hline Tensile strength (MPa) & 1500 & 1880 \\
Tensile modulus (GPA) & 70 & 94 \\
Elongation at break (\%) & 2.14 & 1.9 \\
Compressive strength (MPa) & NA & 720 \\
\hline
\end{tabular}

\subsection{Sample preparation}

\subsubsection{Sieving/sieve analysis}

In as-received form, tin-slag was sticky with a tendency of finer size to attach with coarser aggregates. A drying session at $105^{\circ} \mathrm{C}$ lasting 2 hours was introduced for aggregate prior to be sieved by mechanical stirrer using $4 \mathrm{~mm}, 3.18$ $\mathrm{mm}, 1.4 \mathrm{~mm}, 2 \mathrm{~mm}$ and 1-mm mesh sizes.

In accordance with a reported study seeking least void content, fineness modulus of three finer sizes i.e. $2 \mathrm{~mm}, 1.4$ $\mathrm{mm}$ and $1 \mathrm{~mm}$ were calculated to determine their concentration in total mixture [16]. Sieve analysis in conformity with ASTM C136 / C136M - 14 was carried out to calculate fineness modulus of 3.71, 3.07 and 2.85 for $2 \mathrm{~mm}, 1.4 \mathrm{~mm}$ and $1 \mathrm{~mm}$, respectively. The Fineness modulus is an empirical figure obtained by adding the total percentage of the sample of an aggregate retained on each of a specified series of sieves and dividing the sum by 100 . A $200 \mathrm{~g}$ of aggregate was taken for analysis and three repetitions were carried out to take the average of them for final calculation.

\subsubsection{Polymer concrete (PC) casting}

Table 3 shows the values of fineness modulus along with percentage of coarse and fine aggregates for each of the group. Values of fineness modulus were put into Eq. (1) to get aggregate fraction finer than larger size fraction for each group.

$$
\mathrm{Y}=7.57 \mathrm{X}+27.22
$$

Where

$\mathrm{Y}=$ Proportion of aggregate finer than larger size aggregate

$\mathrm{X}=$ Fineness modulus

Specimen of $50 \mathrm{~mm}$ diameter and $100 \mathrm{~mm}$ height were cast in PVC tubes, used as mold, by mixing pre-calculated proportion of resin, aggregate and initiator before pouring into mold. Curing was allowed for three days in a temperature range of $25-30^{\circ} \mathrm{C}$. For this study, one half of the coarser size aggregate was considered finer size aggregate. Aggregate to resin ratio was set at 70:30 percent by weight. Sample preparation was carried out under the guidelines of ASTM C 192/470.

\subsubsection{Confinement}

Carbon and glass fabrics of rectangular shape were cut into defined dimensions of $100 \mathrm{~mm}$ width and $207 \mathrm{~mm}$ length. Circumference of the specimen was calculated to be 157 $\mathrm{mm}$ with an additional $50 \mathrm{~mm}$ for overlap. Epoxy resin was applied on carbon and glass fabric adopting wet layup process. Similarly, in another repetition, epoxy was applied on the surface of specimen. Next, epoxy impregnated carbon and glass fiber were wrapped on the specimen in hoop direction. An outlook of test specimen is provided in Figure 1. All of the confinement activity was carried out under the guidelines of American Concrete Institute guideline ACI 440.2R-08. Details of confinement plan is given in Table 4.

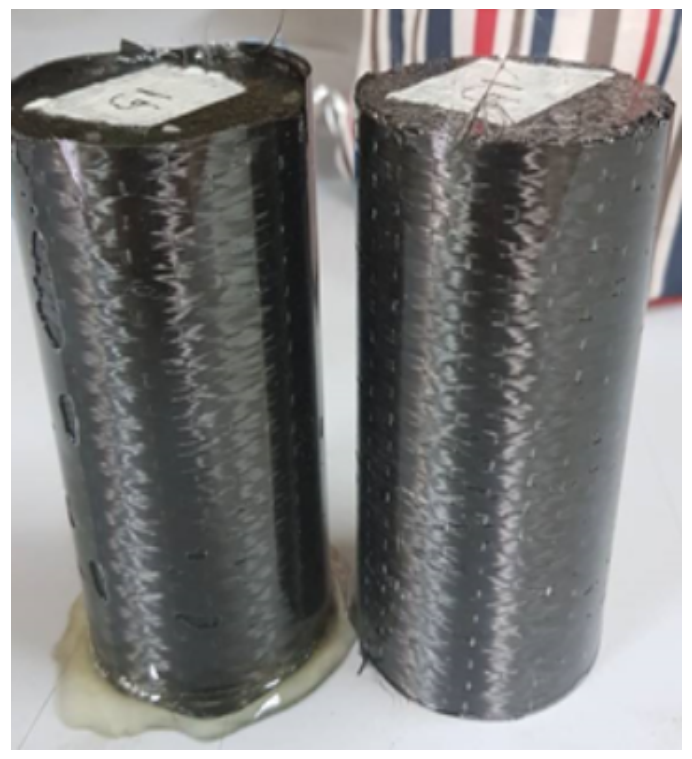

Figure 1: An outlook of confined samples 
Table 3: Detailed sample mixture proportion plan

\begin{tabular}{ccccccc}
\hline $\begin{array}{c}\text { Sample type } \\
\text { (Group) }\end{array}$ & $\begin{array}{c}\text { Resin (g) } \\
\mathbf{( 3 0 \% )}\end{array}$ & $\begin{array}{c}\text { Aggregate (g) } \\
\mathbf{( 7 0 \% )}\end{array}$ & $\begin{array}{c}\text { Total weight } \\
\mathbf{( g )}\end{array}$ & $\begin{array}{c}\text { Coarse } \\
\text { aggregate (g) }\end{array}$ & $\begin{array}{c}\text { Fine } \\
\text { aggregate (g) }\end{array}$ & $\begin{array}{c}\text { Fineness } \\
\text { modulus of finer } \\
\text { aggregate }\end{array}$ \\
\hline $\mathbf{4 + 2}$ & 210 & 490 & 700 & 219.03 & 270.97 & 3.71 \\
$\mathbf{( A )}$ & & & & $(44.69 \%)$ & $(55.30 \%)$ & \\
$\mathbf{3 . 1 8 + 1 . 4}$ & 210 & 490 & 700 & 242.79 & 247.20 & 3.07 \\
(B) & & & & $(49.54 \%)$ & $(50.45 \%)$ & \\
$\mathbf{2 + 1}$ & 210 & 490 & 700 & 250.92 & 239.07 & 2.85 \\
(C) & & & & $(51.20 \%)$ & $(48.79 \%)$ & \\
\hline
\end{tabular}

Table 4: Test sample confinement details

\begin{tabular}{|c|c|c|c|c|c|c|c|c|}
\hline Group & $\begin{array}{c}\text { Aggregate } \\
\text { size }(\mathrm{mm})\end{array}$ & $\begin{array}{c}\text { Control } \\
\text { specimens }\end{array}$ & $\begin{array}{c}\text { Total no. of } \\
\text { specimens } \\
\text { confined (CFRP) }\end{array}$ & $\begin{array}{c}\text { Total no. of } \\
\text { specimens } \\
\text { confined (GFRP) }\end{array}$ & $\begin{array}{l}\text { No. of } \\
\text { layers: } \\
1 \\
\text { (CFRP) }\end{array}$ & $\begin{array}{l}\text { No. of } \\
\text { layers: } \\
1 \\
\text { (GFRP) }\end{array}$ & $\begin{array}{l}\text { No. of } \\
\text { layers: } \\
\quad 2 \\
\text { (CFRP) }\end{array}$ & $\begin{array}{l}\text { No. of } \\
\text { layers: } \\
2 \\
\text { (GFRP) }\end{array}$ \\
\hline A & $4+2$ & 3 & 6 & 6 & 3 & 3 & 3 & 3 \\
\hline B & $3+1.5$ & 3 & 6 & 6 & 3 & 3 & 3 & 3 \\
\hline \multirow[t]{2}{*}{ C } & $2+1$ & 3 & 6 & 6 & 3 & 3 & 3 & 3 \\
\hline & & Total: 09 & Total: 18 & Total: 18 & & & & \\
\hline
\end{tabular}

\subsection{Testing}

Instron $600 \mathrm{kN}$ Universal Testing Machine was operated at a loading rate of $1 \mathrm{~mm} / \mathrm{min}$ in compression mode. Figure 2 shows specimen mounted at the middle of platen to ensure effective distribution of load. Testing activity was performed in accordance with ASTM C579-01 formulated for polymer concrete. Load-deformation behavior, strength, modulus and absorbed energy values were obtained through data acquisition system.

\subsection{Nomenclature}

Group A (4+2 mm), B (3.18+1.4 mm) and C (2+1 mm) refer to aggregate size. Alphabet " $U$ " refer to unconfined state. 1 and 2 in codes A1G and A2G are indicating number of layers. Whereas, " $G$ " and " $C$ " denote glass and carbon fiber composites. So, for instance, $\mathrm{C} 2 \mathrm{C}$ identifies with aggregate size $2+1 \mathrm{~mm}$ and 2 layers of CFRP.

\section{Results and discussion}

This section presents the results for both unconfined and confined PC samples. Discussion and analysis on stressstrain responses, compressive strength, modulus and duc-

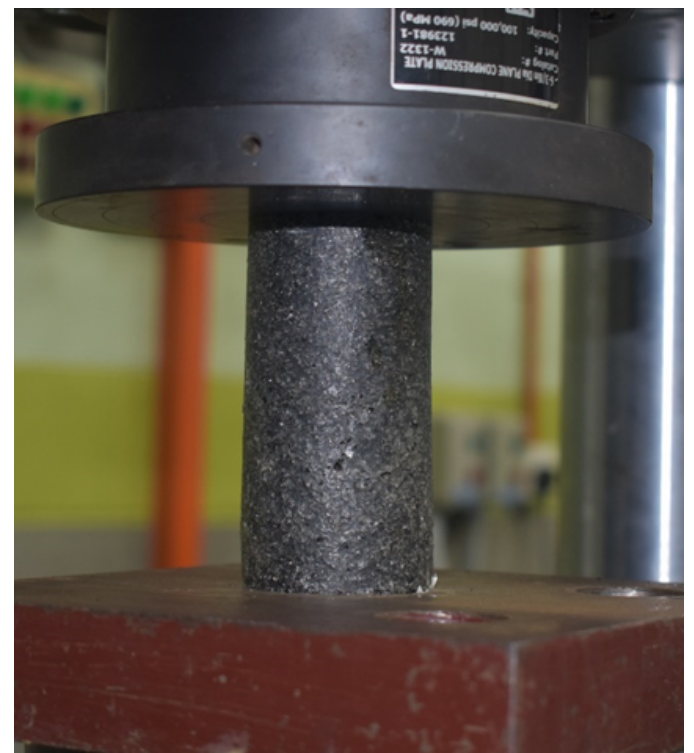

Figure 2: Compression testing of PC

tility indices will be carried out in the light of confinement efficiency. Table 5 provides detailed test data acquired through compression testing. 


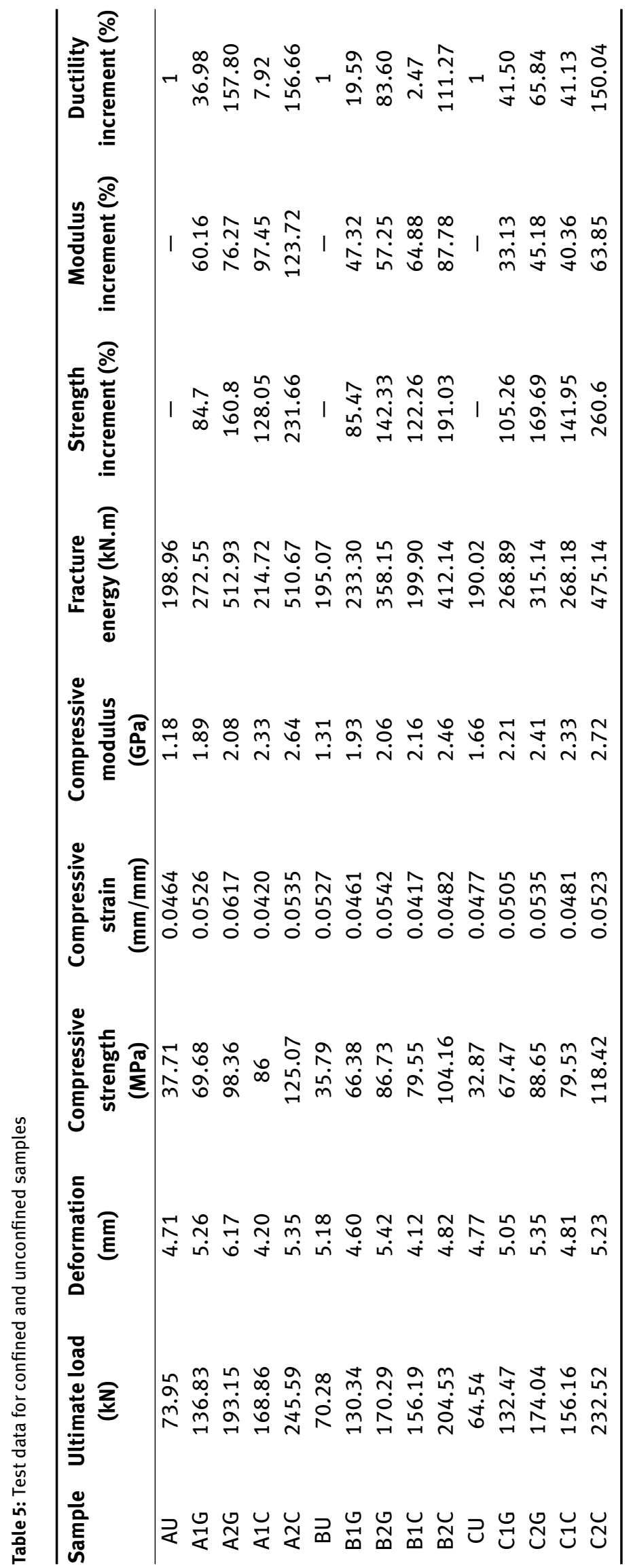




\subsection{Unconfined polymer concrete}

\subsubsection{Stress-strain response}

Figure 3 shows the mechanical response of tin-slag polyester polymer concrete under compression for all aggregate sizes. The basic response of three samples is identical with three distinct zones of curve i.e. ascending, semihorizontal and post-peak descending.

First zone (Ascending) shows steady rate of increse in stress with associated strain. Initial short linear portion of curve is induced by adjustment of platen with the surface of specimen. This portion is marked by extra strain at low value of stress. At the end of it starts the consistent response of composite system where stresses are being distributed equally across the available area. Almost linear trend of ascending region in all samples confirms the effective interaction of heterogeneous elements within the composite system in providing structureal response.

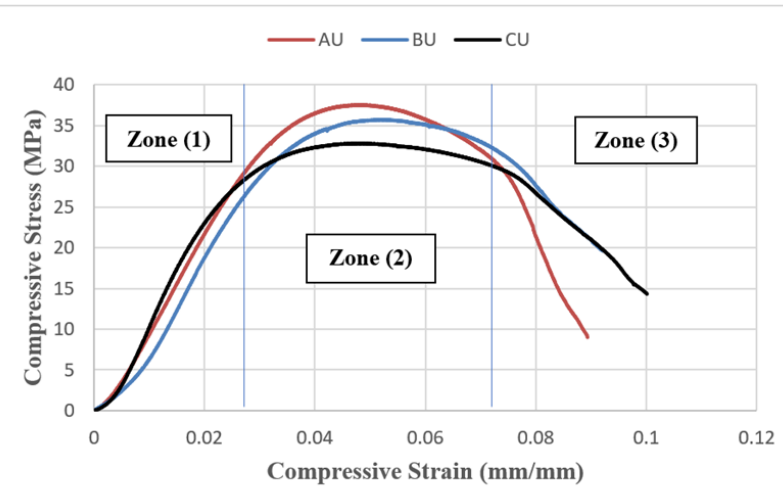

Figure 3: Graph of stress versus strain of unconfined polymer concrete

Second zone (near-horizontal) starts where gradient, apparent in first zone, starts to diminsh to give way to horizontal semi-linearity. Stress in this zone remains near to ultimate strength value accompained by large degree of deformation. This behavior is induced by the gap-graded configuration of aggregate which renders the structure with least void content, thereby, evoking identical elastic deformation response from across the sample.

Third zone (post-peak descending) incorporates fracture driven response. After attaining maximum stress which is associated with fracture of specimen, there will be steady decline in stress value. At this stage, structure will fail to behave cohesively to the applied load and starts to release absorbed energy in the form of propagation of cracks. Also, there will be detachment of aggregates from matrix which is a result of interphase failure [17].

\subsubsection{Mechanical properties}

Figure 4 exhibits the compressive strength and modulus values for all aggregate size samples. With the increase in aggregate size for gap-graded configuration, compressive strength increases continuously with the highest value of 37.7 MPa for AU. For gap-graded aggregates of coarsest size, this increment of compressive strength was attributed to effective distribution of finer size $(2 \mathrm{~mm})$ in granular skeleton because of two factors i.e. angular shape and higher concentration. As a principle, concentration of finer aggregates in gap-graded mixture increases with fineness modulus of finer aggregate. This will increase the likelihood of finer size getting place between coarser aggregates thus providing cushioning effect. Also, angular shape will reduce the segregation of aggregates during mixing and settling in curing stage. On the other hand, spherical particles that abounds in finer sizes have a tendecy to segregate during mixing at sample preparation stage.

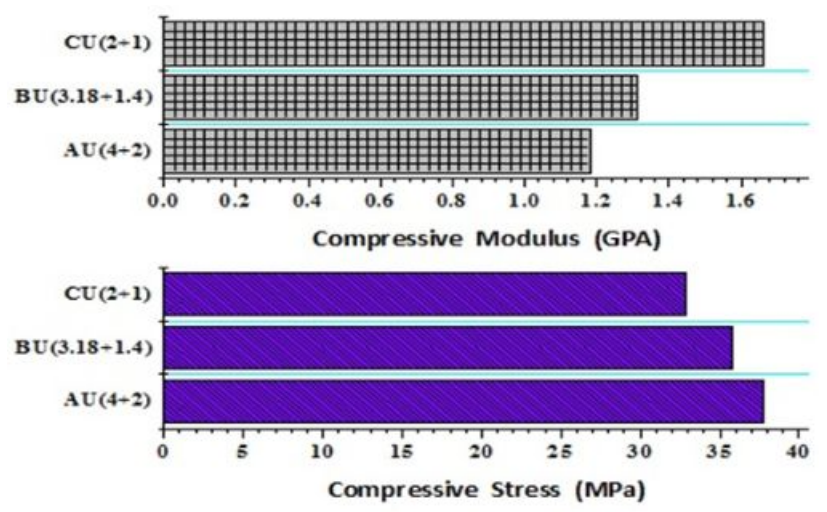

Figure 4: Graph of PC compressive strength and modulus variation with aggregate size

Compressive modulus of PC increases with decrease in aggregate size. This phenomenon has been noticed in case of portland cement concrete when the aggregate size range adopted was 3 to $14 \mathrm{~mm}[18,19]$. The rationale for this increment in modulus is the volumetric increase in interphase which increases with the the availabilty of surface area. This relation has been reported in a study considering polymer cementitious compounds where modulus is considered to be the product of two phases: aggregate and interphase [19]. 
Figure 5 juxtaposes the compressive strength and modulus trends acquired across the three aggregate groups. The contrasting relation of strength and modulus is evident induced by variation in aggregate size.

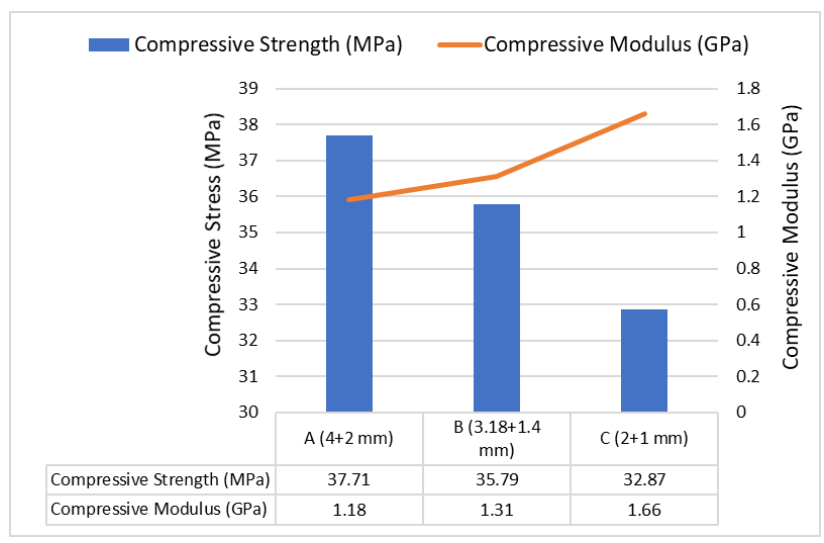

Figure 5: Graph of comparison of compressive strength and modulus variation with aggregate size

\subsection{Confined polymer concrete}

\subsubsection{Load-deformation behavior}

Figure 6 shows the compressive behavior for GFRP and CFRP confined samples. Unconfined sample curves are inserted as reference. FRP confined PC showed typical bilinear curve but with sharp transition from core-induced to jacket-induced region in the curve. The convention of assuming response from concrete core in first linear region and from jacket in second linear region, in case of ordinary concrete, does not seem to hold true for polymer concrete.

In general, curves for GFRP confined samples show identical behavior regardless of aggregate size. The bilinear trend is obvious but with differences in initial sections of the curve. For $\mathrm{A} 1 \mathrm{G}$ and $\mathrm{A} 2 \mathrm{G}$, the inital response is same as that of unconfined sample AU. Same slope of the curves regrdless of confinement indicates that the granular skeleton of the strucutre is effecient enough to support the load untill it reaches around 54\% (39 kN) of maximum load sustained by uncofined specimen. At this point, curves of the confined specimen start to diverge from the common path. This behavior does not match with that of confined portland cement concrete where curve region representing confinement emerges when the load is around peak load of unconfined concrete [20-22]. This results from the much higher value of modulus of elasticity of concrete (14$41 \mathrm{GPa}$ ) which attracts major part of the load in the first re- gion of bilinear curve. For B1G, B2G, C1G and C2G, curves start to diverge almost immediately after the onset of load. This change of slope to higher position indicates that polymer concrete granular structure, itself unable to carry load, starts to transfer it to the jacket.

Even with the reduced capacity of polymer concrete to carry load with reduction in aggregate size, the role of concrete core is evident in the load-displacement response of confined specimen. Both, for A1G and A2G first linear region contains mixed reaction from both jacket and core, but second linear region is primarily influenced by pressure generated by jacket. This is causing declivity in slope at higher regions of the curves.

The typical two linear regions are noticeable in case of CFRP but with transition zone which is much sharper than GFRP confined sample curves. This is because of high stiffness of the carbon fiber composite which is sensitive to minute expansion of the concrete core. As the contribution from stiffer jacket to support load starts from the onset of experiment, the transfer of load to jacket, as principal load bearing component, becomes less noticeable. This fact has been verified in a study that reports mechanical properties of jacket and their thickness at forefront in giving performance of ordinary strength concrete (20 to 50MPa) [23].

When performance of one layer samples is compared with two layers, the effect of concrete core becomes evident especially for higher strength samples of group A. Group A is distinguished from group B and C in showing a greater matched region of curves (up to $86.24 \mathrm{kN}$ ) for one and two layers CFRP. However, for group B and C, this region of identical slope is reducing. For Group $\mathrm{B}$, this region extends upto $62.72 \mathrm{kN}$; and for Group C, it resides below $30 \mathrm{kN}$. Such a behavior is dictated by the load bearing capacity of concrete core, which sees a declining trend from group $\mathrm{A}$ to $\mathrm{C}$. This finding has also been reported in a study conducted on normal and high strength concrete wrapped with CFRP. Stress-strain curves for one, two, and three layers exhibit a longer region of close values of slope when strength of core increases from $32 \mathrm{MPa}$ to $107 \mathrm{Mpa}$ [24].

\subsubsection{Mechanical properties}

Figures 7 and 8 outline the compressive strength of samples and increment in strength with number of layers. Group A, in conformity with the results of unconfined samples, shows the highest degree of increase in strength both for carbon and glass fiber composites which can be appreciated by observing consistent slope with number of layers in Figure 8. This is precisely because of the same reason as of the unconfined sample i.e. granular skeleton is 


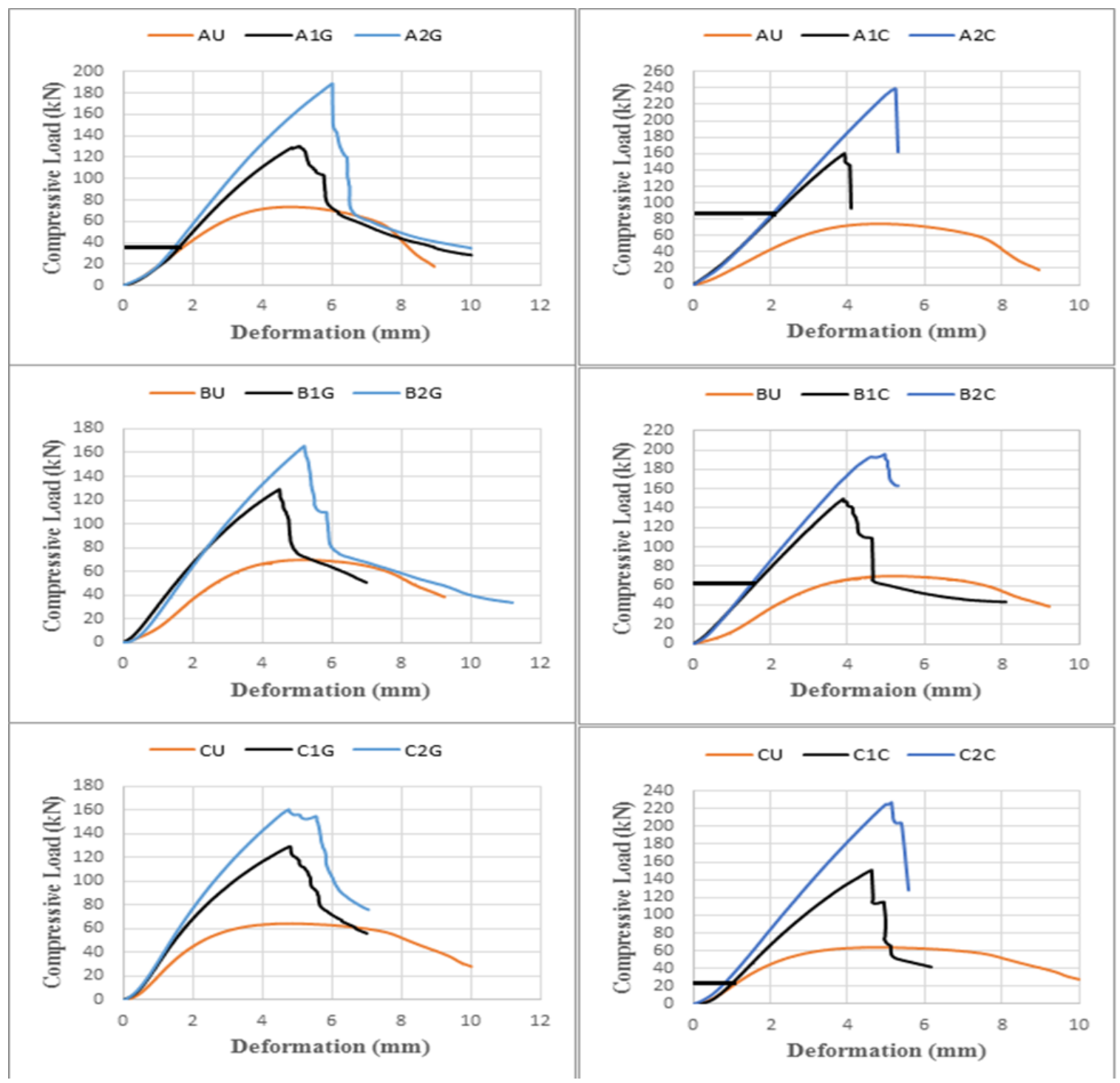

Figure 6: Graphs of load versus deformation of groups A $(4+2 \mathrm{~mm}), B(3.18+1.4 \mathrm{~mm})$ and C $(2+1 \mathrm{~mm})$ confined with GFRP and CFRP (Black lines indicate extent of shared path of curves)

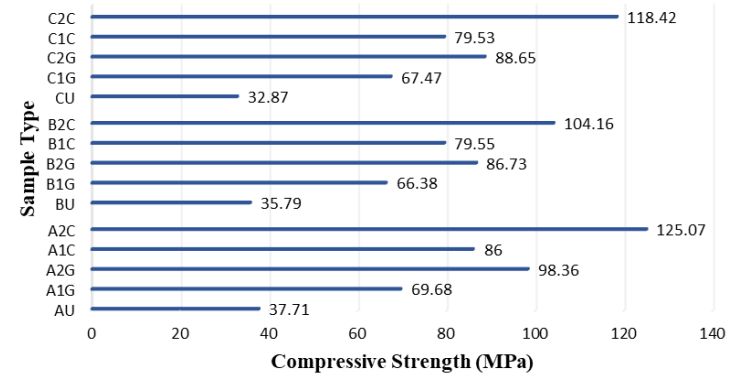

Figure 7: Bar-chart of compressive strength of CFRP/GFRP confined polymer concrete well distributed to support structural load. One layer of glass has increased the ultimate strength to about $84.7 \%$ whereas two layers have pushed it to $160.8 \%$ compared to the strength of unconfined sample (37.71 MPa). The same is true of carbon where increase in strength for one layer is $128.05 \%$ and for two layers, $231.66 \%$.

In group $\mathrm{B}$, the percentage increment in strength for one and two layers of GFRP is $85.47 \%$ and $142.33 \%$. This loss of effeciency can be glimpsed in Figure 8 (Group B). For CFRP, theses values are $122.26 \%$ and $191.03 \%$ for one and two layers. For group C, one layer of glass offers $105.26 \%$ increase whereas two layers give $169.69 \%$. One ply of carbon gives $141.95 \%$ and two layers $260.26 \%$ increment in strength. The whole result spectrum has been summarized in Table 5. 


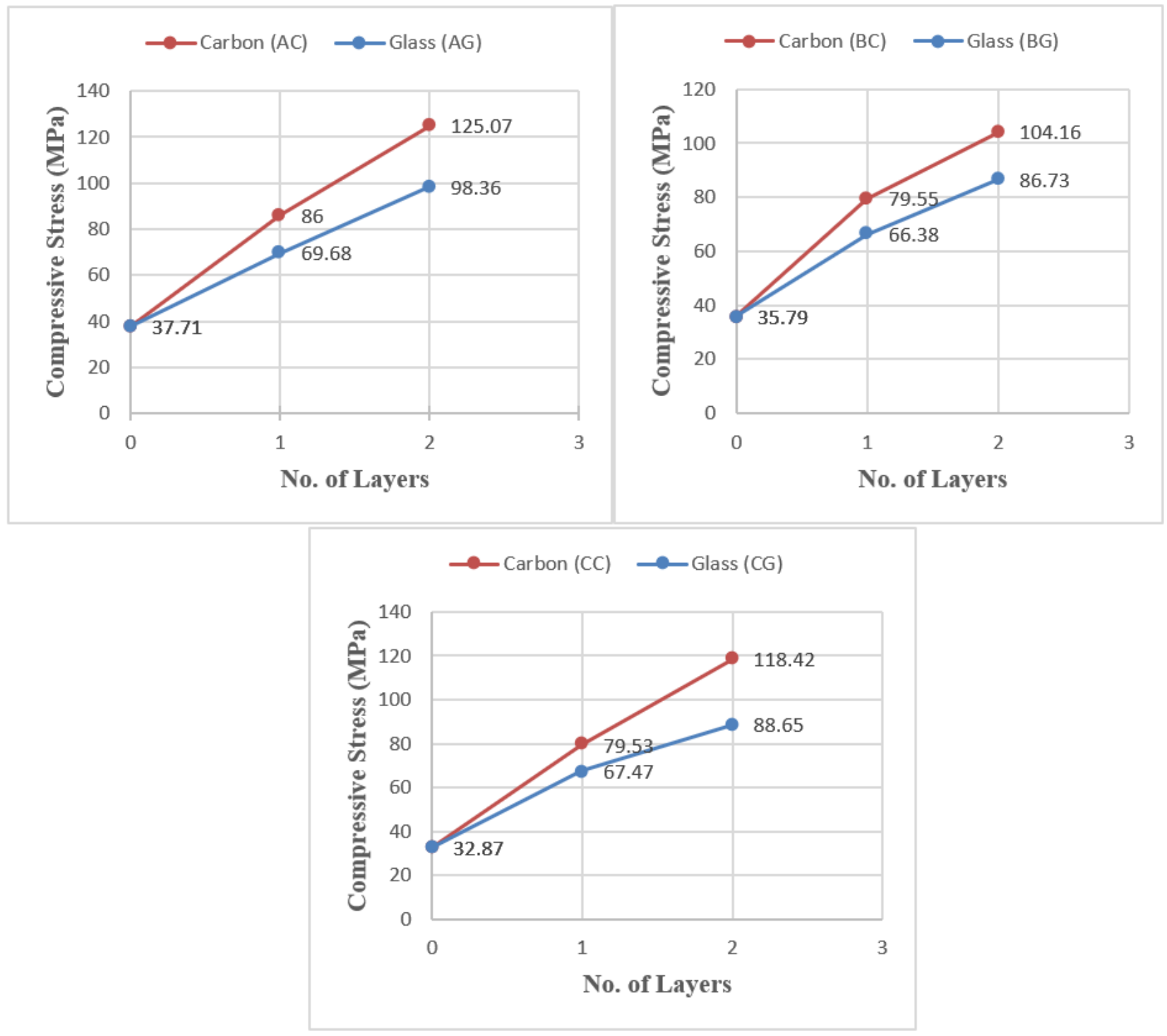

Figure 8: Graphs of compressive strength versus no. of layers for gorups A ( $4+2 \mathrm{~mm}), B(3.18+1.4 \mathrm{~mm})$, and C ( $2+1 \mathrm{~mm})$

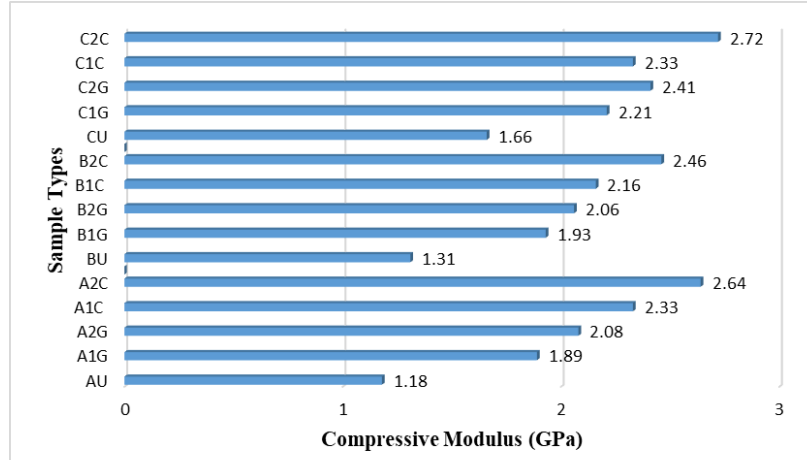

Figure 9: Bar-chart of compressive modulus of group A, B and C confined samples
Compressive strength increment within group B and C confined samples follow the same trend as that of group A; but across both groups, properties of samples occasionaly overlap or closely lying to each other. This happens because of reduction in aggregate size, values of fineness modulus of finer sizes ( 1.4 and $1 \mathrm{~mm}$ ) lying close to each other, greater control of jacket on properties with reduction in core strength and reduced effeciency of gap-graded principle for finer sizes.

Figure 9 provides an outlook of increment in modulus with confinement for three group sizes. The dominent feature of bar-chart of modulus is ascending trend with the increase in number of layers for both CFRP and GFRP across groups. Summary of modulus values are given in Table 5. 


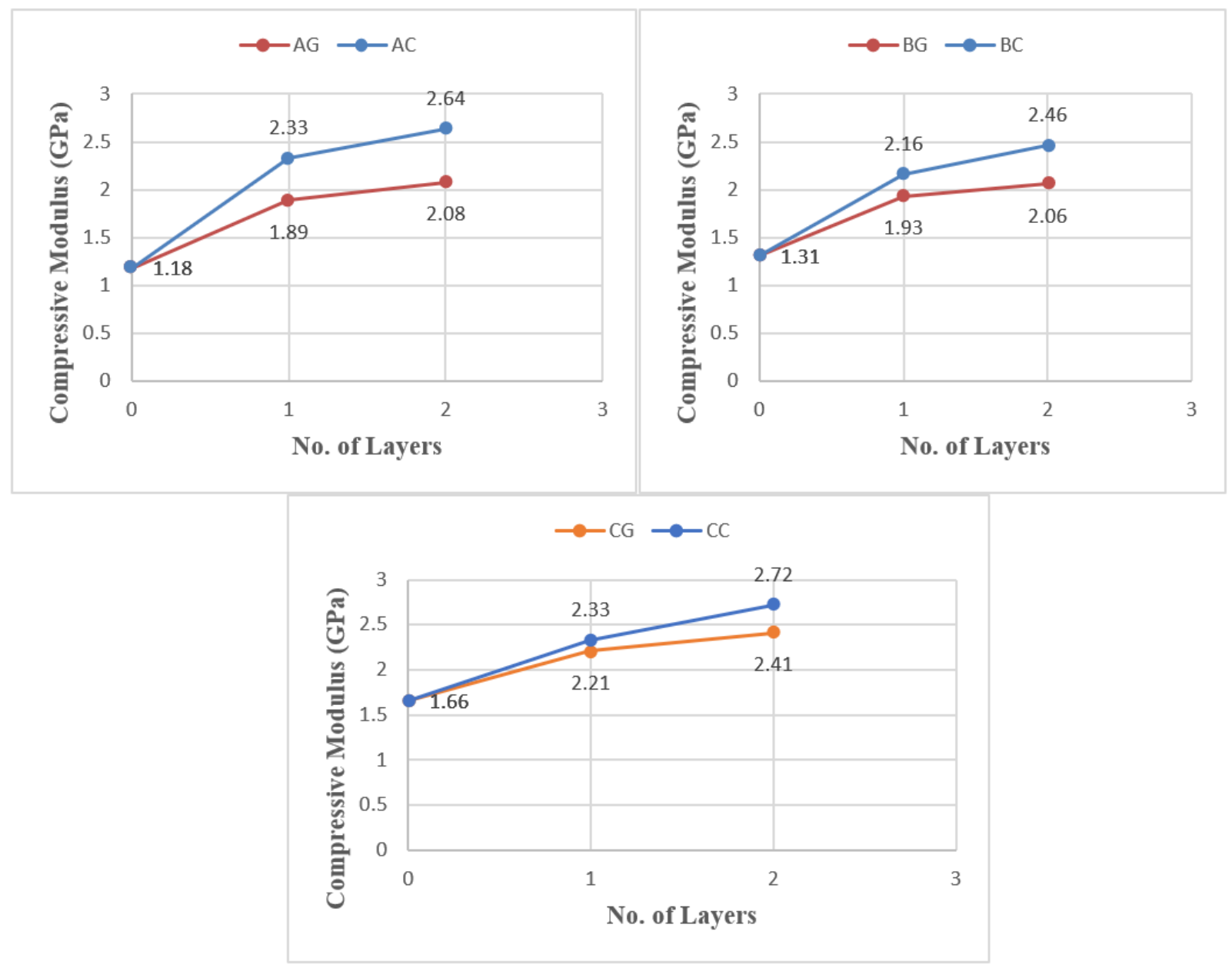

Figure 10: Graphs of compressive modulus versus no. of layers for gorups A $(4+2 \mathrm{~mm}), \mathrm{B}(3.18+1.4 \mathrm{~mm})$, and C $(2+1 \mathrm{~mm})$

It is true in case of modulus, as in case of ultimate strength, that the lower the value of modulus of concrete core, higher will be the effectiveness of confinement in influencng ultimate value of modulus. This is evident in case of group A (Figure 10) which has lowest value of modulus $1.18 \mathrm{GPa}$. But, the values of confined samples are comparable/closer to group $\mathrm{C}$ samples that has highest concrete core modulus of $1.66 \mathrm{GPa}$.

This finding that modulus values of confined samples do not increase substantially/proportionally as the modulus of control/unconfined sample increases, leads to the realization that FRP is controlling the ultimate values of modulus for the confined system. Seemingly, closely lying/overlapping values of modulus across groups is because of FRP properties with inconsequential effect from polymer concrete. The influence of polymer concrete is, also, difficult to analyze becasue of the slight increment in modulus value from 1.18 to $1.66 \mathrm{GPa}$ across groups which can not translate into a meaningful distinctive performance.
Another fact testifies this conclusion, and that is stiffness of FRP composite. Carbon confined samples have higher percentage increment than glass that indicates role of FRP's stiffness in controlling ultimate value of modulus for confined configuration (Figure 10).

Table 5 shows the fracture energy values of each sample. The values of fracture energy have been acquired by calculating area under load-displacement curve with a basic assumption that as soon as the maximum load reaches, specimen undergoes sudden failure [13]. Figure 11 presents variation in ductility indices with no. of layers for three confined groups. Ductility indices are a ratio of fracture energy values of confined to unconfined specimens.

It can be observed that fracture energy increases with the addition of FRP layers i.e. it can absorb more energy than unconfined sample before failure. For group A, ductility indices reach $157 \%$ and $156 \%$ for two layers of glass and carbon composites. These are the highest indices in all three groups partly becasue highest values of extention at 


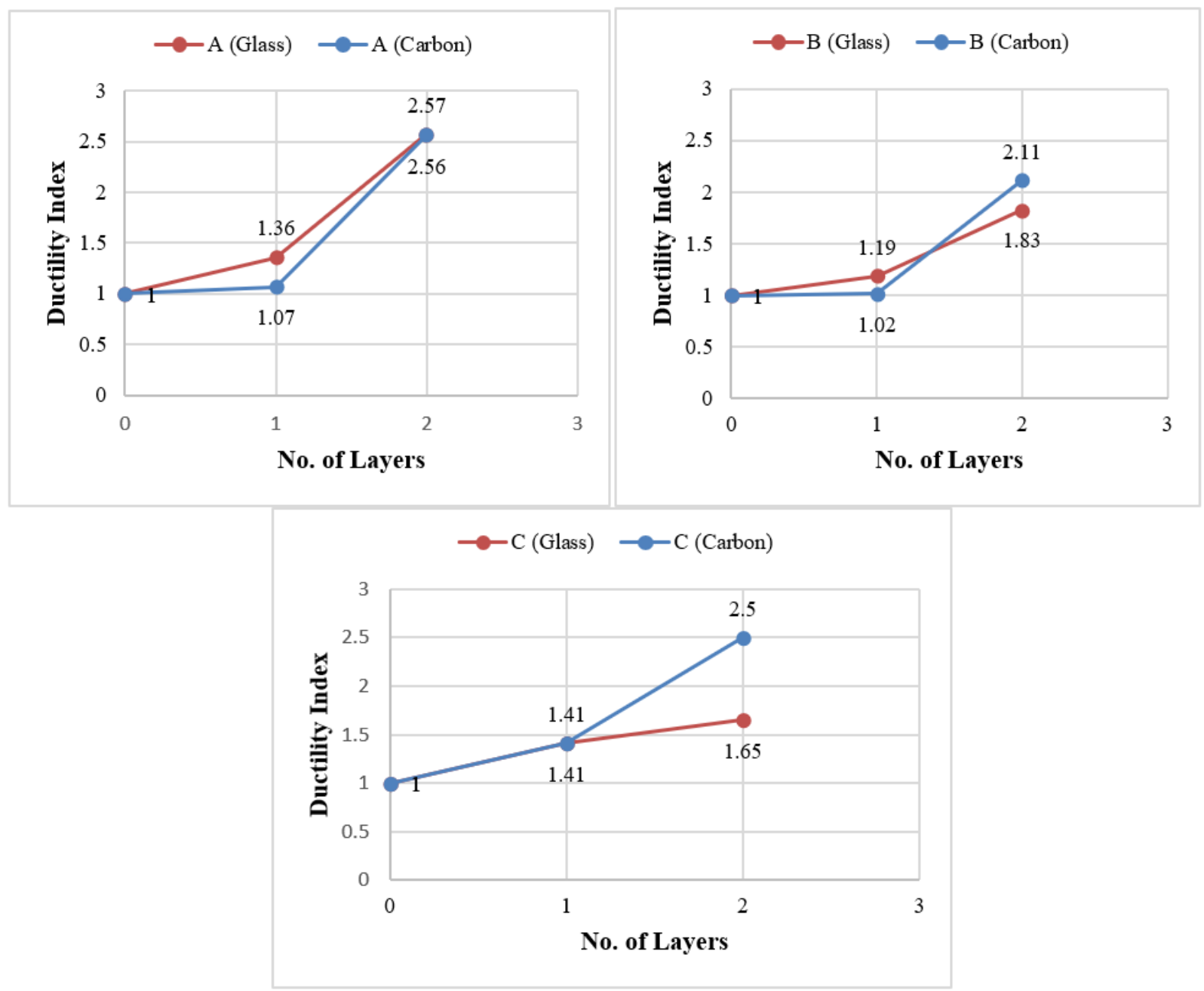

Figure 11: Graphs of ductility indices versus no. of layers for gorups A ( $4+2 \mathrm{~mm}), \mathrm{B}(3.18+1.4 \mathrm{~mm})$, and C $(2+1 \mathrm{~mm})$

maximum load recorded for these samples are i.e. $6.17 \mathrm{~mm}$ and $5.35 \mathrm{~mm}$ for GFRP and CFRP.

For one layer samples of both CFRP and GFRP of group A and C, results do not produce a clear trend. Group B represents lowest indices of all groups and types of fibers. That is because of factors affecting the area under curve such as low ultimate load value and displacement. Influence of these competing factors is appreciated by the fracture energy of unconfined samples AU, BU and CU. AU has the highest value of fracture enegy, primarily, owing to highest value of strength whereas $\mathrm{BU}(5.18 \mathrm{~mm})$ and CU (4.77 $\mathrm{mm}$ ) can undergo larger displacement than group A according to data.

It is logical to observe the better performance of GFRP confined polymer concrete in absorbing energy than CFRP. This comes from the materials properties of GFRP which has way low stiffness than CFRP. Also, ductility increment of GFRP confined sample shows competing (A2G) and bet- ter (A1G) perofrmance than CFRP confined counterparts in terms of absorbed energy although it has lower strength than CFRP.

\subsection{Failure modes}

Figure 12 shows the typical failure modes for unconfined and FRP confined tin slag/polyester polymer concrete. The shear cone formations failure (Yellow circle) of PC was evident in all sample types regardless of aggregate sizes. This results from the fact that $\mathrm{PC}$ has little tensile strength as compared to compressive strength. Accordingly, with the onset of axial load, tensile stresses in the shear planes starts to generate. As these stresses begin to exceed the tensile strength of material, failure occurs [25].

Shear cone formation is more pronounced in the central part of specimen than at the periphery. This confirm the proposition that stress distribution in the middle are 

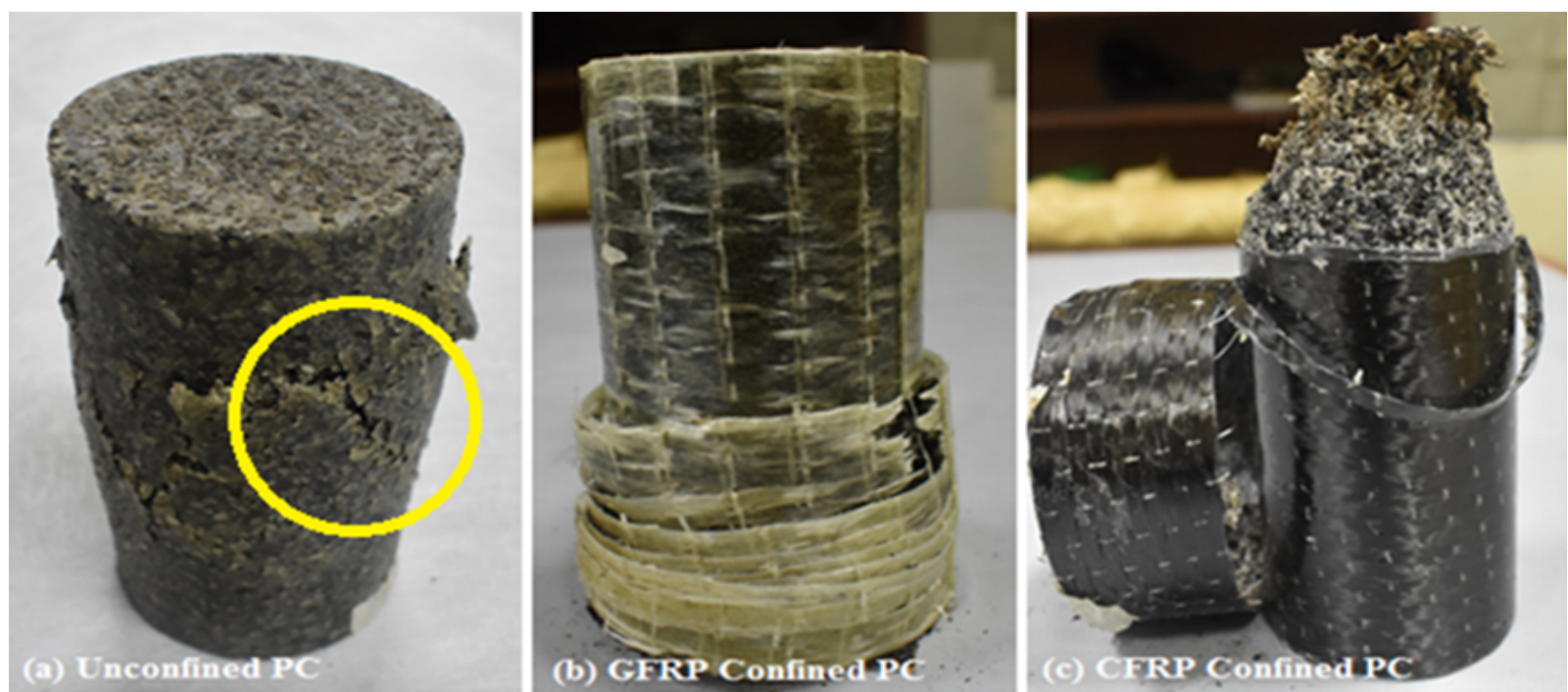

Figure 12: Characteristic failure modes of (a) unconfined PC (b) GFRP confined PC and (c) CFRP confined PC

higher than at fringes of the cylindrical radius. This higher stress distribution is activating failure planes in the middle part of the specimen.

GFRP confined PC failure is characterised by steadiness and graduality. The distinguished feature is layer by layer failure called ringed rupture (Figure 12 (b)). It can be seen that the failure is centered at bottom part of the specimen. This feature is primarily dictated by the direct exposure of jacket to compressive load from the lower crosshead, that is moving up. The crushed core confirms that jacket was holding the load primarily after failure of core, around maximum load of unconfined specimen. The gradual failure is induced by the greater percentage elongation property of GFRP which helps it store and release energy in a systematic way. With the foramtion of every ring of jacket, some of the energy is released. This process continues untill there is no more stored energy in the confined system.

CFRP failure is abrupt and sudden. The greatest drawback of CFRP lies in its capacity to store energy which is exponentially larger than the concrete core can sustain. As the jacket failure occurs, the energy is released rapidly and the load is abruptly transferred to core, causing loud noise. This caused the top half of the core to be demolish as can be seen in Figure 12 (c) [26]. Also, CFRP exhibited a disticnt jacket failure that can be called debonding. It was observed predominently in case of one layer specimens and was the most catastrophic of all failures.

\section{Conclusion}

This study attempted to share compressive behavior and properties of a tin slag/polyester polymer concrete both in confined and unconfined cases. One and two layers of CFRP/GFRP were used to confine PC to assess their performance under compression. Following conclusions were drawn from the activity:

1. Group A $(4+2 \mathrm{~mm})$ offered highest compressive strength of $37.71 \mathrm{MPa}$ in gap-graded configuration. Effective distribution of granular skeleton due to higher concentration of finer size was primary cause of this performance.

2. Compressive modulus decreased with the increase in aggregate size owing to reduction in interphase volume. Highest modulus of $1.66 \mathrm{GPa}$ was noted for group C $(2+1 \mathrm{~mm})$.

3. Compressive strength, modulus and ductility of confined systems increased proportionally with number of layers both for CFRP and GFRP. Highest strength was given by two layer GFRP and CFRP i.e. $98.36 \mathrm{MPa}$ $(160.8 \%)$ and $125.07 \mathrm{MPa}(231.66 \%)$.

4. Failure mode of unconfined system was gradual and steady marked by shear cone formation in the middle part of specimen. GFRP confined samples failed with gradual release of absorbed energy whereas CFRP ones underwent sudden/explosive failure characterised by debonding.

It was concluded that the fundamental behavior of confined tin slag/polyester concrete was different from portland cement concrete. Role of FRP confinement is 
much more pronunced in controlling stress-strain behavior and mechanical properties of polymer concrete. Also, core and jacket replaces each others role depending upon the inherent properties of two components i.e. weaker core will be controlled by jacket and vice versa.

Conflict of Interests: The authors declare no conflict of interest regarding the publication of this paper.

Acknowledgement: Authors are thankful to Universiti Teknologi Malaysia for the financial support provided under Vote Number: Q.J130000.2424.03G89. Also, due regard is payed to Higher Education Commission, Pakistan for financial support it provided to first author.

\section{References}

[1] Malhotra V.M. and Mehta P.K., High-performance, high-volume 15 fly ash concrete: Materials, mixture proportioning, properties, construction practice, and case histories, 2002, Supplementary Cementing Materials for Sustainable Development Ottawa.

[2] Osborne G). Durability of portland blast-furnace slag cement concreto. Cem. Concr. Compos. 1999;21(1):11-21.

[3] Binici H, Shah T, Aksogan O, Kaplan H. Durability of concreto made with granite and marble as recycle aggregates. J Mater Process Technol. 2008;208(1-3):299-308.

[4] Kumar Mehta P, Paulo JM. Monteiro, Concrete: Microstructure, Properties, and Materials. 4th ed. McGraw-Hill Education. 2014.

[5] Bedi R, Chandra R, Singh S. Reviewing some properties of polymer concrete. Indian Concr J. 2014;88:47-68.

[6] Fowler DW. Polymers in concrete: A vision for the 21st century. Cement Concr Compos. 1999;21(5-6):449-52.

[7] Figovsky O, Beilin D. Advanced polymer concretes and compounds. CRC Press. 2013.

[8] Carrión F, Montalbán L, Real JI, Real T. Mechanical and physical properties of polyester polymer concrete using recycled aggregates from concrete sleepers. Scientific World Journal. 2014;2014:526346.

[9] Jung KC, Roh IT, Chang SH. Evaluation of mechanical 35 properties of polymer concretes for the rapid repair of runways. Compos, Part B Eng. 2014;58:352-60.

[10] Ferdous W, Manalo A, Aravinthan T, Van Erp G. Properties of epoxy polymer concrete matrix: effect of resin-to-filler ratio and determination of optimal mix for composite railway sleepers, 40 . Constr Build Mater. 2016;124:287-300.
[11] Yin P, Huang L, Yan L, Zhu D. Compressive behavior of concrete confined by cfrp and transverse spiral reinforcement. Part a: experimental study. Mater Struct. 2016;49(3):1001-11.

[12] Qureshi LA, Ahmad J, Salahuddin H. Seismic vulnerability assessment of strengthened glass fiber reinforced concrete 45 (gfrc). KSCE J Civ Eng. 2017;21(6):2235-44.

[13] Ghalieh L, Awwad E, Saad G, Khatib H, Mabsout M. Concrete Columns Wrapped with Hemp Fiber Reinforced Polymer - An Experimental Study. Procedia Eng. 2017;200:440-7.

[14] Yusof MA. Investigating the potential for incorporating tin 50 slag in road pavements. University of Nottingham. 2005.

[15] Rustandi A, Wafa'Nawawi F, Pratesa Y, and Cahyadi A. Evaluation of the suitability of tin slag in cementitious materials: Mechanical properties and leaching behaviour. In IOP Conference Series: Materials Science and Engineering. 2018. IOP Publishing. 55.

[16] Rao VK, Krishnamoothy S. Aggregate mixtures for leastvoid content for use in polymer concrete, Cemen. Concre. aggre. 1993;15(2):97-107.

[17] Hwang EH, Kim JM, Yeon JH. Characteristics of poliester polymer concrete using spherical aggregates from industrial by- 60 products. J Appl Polym Sci. 2013;129(5):2905-12.

[18] Elices $M$, Rocco $C$. Effect of aggregate size on the fracture and mechanical properties of a simple concrete. EnFM. 2008;75(13):3839-51.

[19] Manning DG, Hope BB. The effect of porosity on the com- 65 pressive strength and elastic modulus of polymer impregnated concrete. Cement Concr Res. 1971;1(6):631-44.

[20] Xiao Y, Wu H. Compressive behavior of concrete confined by various types of frp composite jackets. J Reinf Plast Compos. 2003;22(13):1187-201.

[21] Teng J, Lam L. Behavior and modeling of fiber reinforced polymerconfined concrete. J Struct Eng. 2004;130(11):1713-23.

[22] Mirmiran A, Shahawy M. Behavior of concrete columns confined by fiber composites. J Struct Eng. 1997;123(5):583-90.

[23] Berthet J, Ferrier E, Hamelin P. Compressive behavior of 75 concrete externally confined by composite jackets. Part a: experimental study. Constr Build Mater. 2005;19(3):223-32.

[24] Eid R, Roy N, Paultre P. Normal-and high-strength concreto circular elements wrapped with frp composites. J Compos Constr. 2009;13(2):113-24.

[25] Rebeiz K, Serhal S, Craft A. Properties of polymer concreto using fly ash. J Mater Civ Eng. 2004;16(1):15-9.

[26] Vincent T, Ozbakkaloglu T. Influence of concrete strength and confinement method on axial compressive behavior of frp confined high-and ultra high-strength concrete. Compos, Part B Eng. 2013;50:413-28. 